\title{
К вопросу о классификации соцсетей: субкоммуникация или средство формирования массового сознания
}

\author{
Елена Самсонова
}

\begin{abstract}
В данной статье автор предлагает новую классификацию социальных сетей, выделяя два их типа: соцсети, способствующие формированию субкоммуникации с уходом в виртуальный мир, и соцсети, активно воздействующие на реальную жизнь пользователей посредством формирования в их сознании определенной картины мира. При этом важным аспектом в контексте выявления указанных типов являются функции, наиболее характерные для определенной социальной сети.

Ключевые слова: социальные сети, классификация социальных сетей, типы социальных сетей, социальносетевая картина мира.
\end{abstract}

DOI: 10.30547/mediaalmanah.6.2020.1219

@ Самсонова Елена Александровна соискатель кафедры стилистики русского языка факультета журналистики МГУ имени М.В. Ломоносова (г. Москва, Россия), elena.girl@inbox.ru

\section{Социальные сети как тип новых медиа}

Первая социальная сеть (Classmates. com) была создана Энди Конрадом еще в 1995 г., однако официальным началом эры социальных сетей следует считать 20032004 гг., когда появились такие платформы, как Facebook и Linkedln. В России первыми социальными сетями стали «ВКонтакте» и «Одноклассники», запущенные в 2006 г. В настоящее время влияние социальных сетей на жизнь общества усиливается, а для многих молодых людей, наиболее активной аудитории соцсетей, коммуникация в Интернете не только становится важной частью повседневной деятельности, но и часто заменяет коммуникацию реальную, что свидетельствует о необходимости исследования соцсетей в различных контекстах, несмотря на существование уже довольно большого объема научных трудов, посвященных данному типу новых медиа.

Понимание социальной сети как платформы, предназначенной для «организации всестороннего общения между реальными людьми в Интернете» (Мансурова, 2016: 11) и характеризующейся рядом особенностей, в частности наличием у пользователей возможности самостоятельно создавать контент, является недостаточным. Названное средство массовой коммуникации представляет собой виртуализированную 
социальную среду, в которой человек формирует и расширяет социальные связи, социализируется и самореализуется (Безбогова, 2016). Более того, это пространство, функционирующее с учетом определенных правил пользования и норм, в рамках которого осуществляется особый тип коммуникации, связанный в том числе со специфическими формами социального одобрения, которые выражаются в виде «лайков», «репостов» и т.д. Данные особенности социальных сетей позволяют рассматривать этот ресурс как полноценный социальный институт (Дукин, 2017).

Многие из предлагаемых исследователями классификаций социальных сетей являются довольно спорными. Так, контентная классификация предполагает выделение социальных сетей, ориентированных на отдельные типы контента (видео - YouTube, фото - Flickr, аудио - Last.fm), и соцсетей общего плана, в которых присутствуют разные типы контента («ВКонтакте», Facebook) (Гуреева, 2016). Однако в настоящее время мы можем наблюдать тенденцию к расширению способов коммуникации в «специализированных» социальных сетях. Например, Instagram, изначально предназначавшийся для публикации фотографий, сейчас позволяет пользователям не только размещать визуальный контент, но и сопровождать его развернутыми подписями и комментариями, проводить опросы в так называемых историях и т.д. С учетом типа социальных связей, устанавливаемых в процессе общения, выделяют соцсети, в которых преобладает личный (Classmates. com) и профессиональный (LinkedIn) типы коммуникации (Мансурова, 2016). Но и в данном случае некоторые социальные сети, например Facebook, часто используются как для личного, дружеского, так и для профессионального (делового) общения. Еще одно основание для классификации соцсетей - доступность. Открытые социальные сети позволяют просматривать аккаунты пользователей неограниченному кругу лиц, а закрытые рассчитаны на конкретный сегмент аудитории, и, как правило, «закрытость» обусловлена типом бизнес-модели проекта (Мансурова, 2016). В современной практике, однако, Facebook, «ВКонтакте», «Одноклассники» и другие соцсети предоставляют своей аудитории возможность менять настройки приватности и делиться контентом с определенными пользователями - например, «друзьями». Таким образом, на наш взгляд, и по способу коммуникации, и по типу социальных связей, и по доступности в настоящее время наиболее характерным для социальных сетей является смешанный тип.

Отметим также, что по географическому признаку социальные сети подразделяют на общемировые (Facebook) и локальные, функционирующие в пределах конкретного региона («ВКонтакте») (Гуреева, 2016). Отдельного внимания заслуживают соцсети, специфика коммуникации в которых заключается в вопросно-ответной форме («Спрашивай.py», Ask.fm, Ask.ru).

В контексте выявления типов социальных сетей предлагаемой нами классификации рассмотрим ряд функций, выполняемых соцсетями. Наиболее значимой является коммуникативная функция, некоторые исследователи при этом подчеркивают важность рекреационной и развлекательной функций, поскольку пользователи часто обращаются к новым медиа с целью проведения досуга (Ефимов, 2014; Першина, 2017). С коммуникативной функцией связана роль социализации, которая выражается в так называемом «френдировании» и восприятии жизненного опыта конкретного круга лиц, виртуальных «друзей». Кроме того, для формирования социального «я» человеку необходимо отождествлять себя с определенной социальной группой, в связи с чем исследователи выделяют идентификационную функцию (Садыгова, 2012). Самоидентификация предполагает в том числе участие пользователя в группах (сообществах) социальной сети 
с учетом его интересов, что позволяет говорить о функции кооперации (Мансурова, 2016). Т.С. Садыгова (2012) также обращает внимание на самоактуализирующую функцию, обусловленную стремлением аудитории удовлетворить потребность в самовыражении и творчестве. В то же время нельзя забывать о том, что, публикуя контент в своем аккаунте, пользователь стремится сформировать у других участников сети определенное впечатление о своей личности - в данном случае речь идет о функции самопрезентации. Соцсети выполняют и другие функции, связанные с поиском информации, получением новых знаний, образованием, саморазвитием и т.д. Данный тип новых медиа также представляет собой платформу для размещения рекламы, публикации средствами массовой информации журналистского контента и взаимодействия СМИ с массовой аудиторией.

\section{Методологические основы новой классификации социальных сетей}

Объектом нашего исследования стали социальные сети «ВКонтакте», Ask.ru и Ask. $f m$. Наибольшей частотностью привлечения в качестве эмпирического материала обладает социальная сеть «ВКонтакте». Она многократно анализировалась исследователями с позиции психологии, социологии, лингвистики, психолингвистики и других наук (см., напр., Матусевич, 2015; Морозова, 2014), что обусловлено популярностью данной платформы (в том числе и у молодых людей). Гораздо реже исследователи обращаются к молодежным соцсетям Ask. ru и Ask.fm (Жаркова, 2016).

В рамках данного исследования впервые проводится сопоставительный анализ особенностей коммуникации в названных соцсетях с целью их классификации. В результате выделены два типа социальных сетей: способствующие формированию субкоммуникации суходом в виртуальный мир и активно воздействующие на реальную жизнь пользователей посредством формирования в их сознании определенной картины мира. При этом важным аспектом в контексте выявления указанных типов являются функции, наиболее характерные для каждой из платформ. Для реализации поставленной цели нами использовались такие общенаучные методы, как наблюдение, анализ, сравнение, описание, систематизация и классификация.

\section{Социальные сети как субкоммуникация}

Одна из особенностей социальных сетей Ask.ru и Ask.fm заключается в специфической вопросно-ответной форме коммуникации, создающей иллюзию прямого общения. Пользователями подобных ресурсов являются исключительно молодые люди, что во многом предопределяет формирование особого типа коммуникации «для своих». По мнению исследователей, молодежь обладает противоречивой психологией: с одной стороны, данная социальная группа стремится к обособлению и уходу от внешнего мира; с другой - для нее чрезвычайно важны процессы коммуникации и самоидентификации (Аргентова, 2015). Названные психологические характеристики молодежной аудитории следует рассматривать как одну из предпосылок формирования субкоммуникации, предполагающей уход в виртуальный мир. Более того, данные социальные сети представляют собой площадку, на которой молодые люди в силу своих психологических особенностей противостоят медиасатиации, то есть пресыщению контентом средств массовой информации, которое является следствием основных стратегий медиадискурсивной деятельности СМИ: стратегии манипуляции, гедонизма, десакрализации, или секуляризации, стратегии «культурного шока» и катастрофы (Анненкова, 2011: 189) и приводит к неспособности массовой аудитории распознавать воздействие, оказываемое на нее СМИ. 
Способы формирования субкоммуникации в исследуемых соцсетях не являются абсолютно идентичными. В частности, сама вопросно-ответная, или диалоговая, форма коммуникации имеет некоторые различия. Отметим, что понятие «вопрос» в контексте данных социальных сетей довольно условно, поскольку многие участники соцсети не задают вопрос в его привычном понимании, а предлагают подписчикам тему для обсуждения, выраженную в форме, отличной от прямого вопроса, или предваряют вопрос развернутым размышлением над определенной проблемой.

В социальной сети Ask.ru молодые люди могут взаимодействовать следующим образом: публиковать вопросы как на страницах других пользователей, так и в своем аккаунте; отвечать на вопросы, заданные другими пользователями; комментировать ответы других пользователей. Наиболее значимой функцией социальной сети Ask.ru следует считать коммуникативную функцию (общение в традиционном понимании). Это связано с тем, что данный ресурс ориентирован в первую очередь на вербальную коммуникацию и ограничивает аудиторию в использовании знаков других семиотических систем, в частности он обладает небольшим набором эмотиконов (по сравнению, например, с «ВКонтакте») и позволяет прикрепить изображение только при ответе на вопрос. Большими возможностями с точки зрения визуальной коммуникации обладает соцсеть Ask. $\mathrm{fm}$. Аудитория данного ресурса может не только задавать вопросы неограниченному кругу пользователей (функция Shoutout) или конкретному человеку, но и сопровождать их изображением. Также использование изображения доступно при ответе на вопрос.

Ключевой, на наш взгляд, составляющей визуальной коммуникации в соцсети Ask.fm является функция «Фотоопрос». В контексте формирования субкоммуникации названная функция интересна тем, что все пользователи, обращающиеся к ней, вынуждены конструировать свою публикацию на основе уже готового макета, позволяющего загрузить только два визуальных элемента (между ними будет стоять VS) и дополнить их вербально. Совершенно противоположная ситуация наблюдается в соцсети Ask.ru: на семиотическом уровне субкоммуникация формируется за счет использования многими участниками сети GIF-изображений, созданных на основе кадров из фильмов, сериалов, передач и т.д., смысл которых непонятен «чужому»; определенного типа графики для написания никнеймов (строчных букв, часто в сочетании со знаками пунктуации). Однако в данном случае это делается добровольно: пользователь, идентифицирующий себя с названной соцсетью, следует ее «негласным правилам».

В социальной сети Ask.fm, в отличие от Ask.ru, функции самоидентификации и самопрезентации оказываются первостепенными (хотя, безусловно, коммуникативная функция также реализуется). Особенно отчетливо это прослеживается при изучении тематической доминанты каждой из социальных сетей. Для Ask.fm базовым следует считать социально-сетевой медиатопик «виртуальный успех», которому фактически подчинен весь процесс коммуникации в данной соцсети. Названный медиатопик обусловлен наличием рейтинга, основанного на количестве «монет», заработанных пользователями за последнюю неделю. «Монеты» представляют собой своего рода виртуальную валюту, вознаграждение, получаемое за коммуникацию в вопросно-ответной форме. В процессе общения пользователи часто просят подписаться на их аккаунт и «пролайкать» публикации. Во многом это связано с тем, что участникам социальной сети Ask.fm доступны два типа «лайков»: классический и неклассический, позволяющий также получать «монеты». По сравнению с Ask.ru, для которого «лайки» менее значимы, в соцсети Ask.fm подобная 
форма социального одобрения является элементом, способствующим формированию субкоммуникации. В данном случае функции самоидентификации и самопрезентации связаны со стремлением молодых людей попасть в еженедельный рейтинг: участие в нем свидетельствует об успехе пользователя как участника соцсети.

В социальной сети Ask.ru на тематическом уровне субкоммуникация формируется за счет трех социально-сетевых медиатопиков ("ролевая игра», "реальная жизнь» и «виртуальная жизнь»), значительно отличающихся оттрадиционных медиатопосов. Так, медиатопик «ролевая игра» является примером особого типа коммуникации молодежи, связанного со специфическими интересами данной социальной группы. «Виртуальная жизнь» также не относится к базовым медиатопосам средств массой информации, несмотря на активное развитие информационно-коммуникационных технологий. Кроме того, в рамках медиатопика «реальная жизнь» пользователи в силу своих психологических особенностей часто обращаются к "нематериальному» миру, что менее характерно для СМИ. Подобный выбор свидетельствует о стремлении молодых людей создать свою особую картину миру, отличную от той, которую формируют СМИ в сознании массовой аудитории, что еще раз подчеркивает важность коммуникативной функции (медиатопики формируются именно в процессе вербальной коммуникации).

Таким образом, процесс формирования субкоммуникации в социальных сетях Ask. ru и Ask.fm обусловлен психологическими и возрастными особенностями аудитории данных ресурсов, техническими возможностями платформ и функциями, наиболее характерными для каждой из соцсетей. Важную роль в процессе формирования субкоммуникации играют социально-сетевые медиатопики, обсуждаемые молодыми людьми, при этом можно утверждать, что данные медиатопики являются устойчивыми и не зависят от тем, характерных для всего медиапространства в конкретный период времени.

\section{Социальные сети как средство формирования массового сознания}

Социальная сеть «ВКонтакте» значительно отличается от других анализируемых нами платформ и имеет более сложное функциональное и техническое устройство. Мы склонны полагать, что данный ресурс представляет собой средство массовой коммуникации, активно воздействующее на аудиторию и формирующее в ее сознании картину мира, необходимую для достижения определенных целей, несмотря на персоналистический характер коммуникации в соцсети. Выступая в роли коллективного организатора, «ВКонтакте» способствует формированию массового сознания и поведения, влияет на реальную жизнь пользователей. Отметим, что в рамках настоящего исследования «ВКонтакте» не рассматривается в качестве площадки, используемой средствами массовой информации для публикации журналистского контента и коммуникации с аудиторией. В качестве эмпирического материала для анализа привлекаются посты, сделанные пользователями в своих аккаунтах, размещенные в группах различной тематической направленности, а также комментарии пользователей в этих группах.

Организаторский и манипулятивный потенциал подобных социальных сетей, в которых реализуется большое количество функций (коммуникативная, кооперирующая, идентификационная, развлекательно-рекреационная, функция самопрезентации и др.), огромен. Не случайно соцсети (в том числе и «ВКонтакте») довольно часто рассматриваются в контекстах политической коммуникации (Зуйкина, Соколова, 2019) и мобилизации общества, в первую очередь молодежи (Манойло, 2015). Исследователями отмечается и преобладание визуального контента в анализируемой 
соцсети. Это обусловлено тем, что значительную часть информации человек получает через органы зрения, при этом именно визуальная коммуникация оказывается наиболее простой и эффективной формой коммуникации (Муронец, 2015). В то же время «ВКонтакте» представляет собой платформу, позволяющую осуществлять различные типы коммуникации: вербальную, визуальную, аудиальную, аудиовизуальную ит.д. Использование креолизованного текста, то есть текста, включающего в себя различные семиотические знаки, образующие «визуальное, структурное, смысловое и функциональное целое» (Анисимова, 1996: 75), способно усилить оказываемое на аудиторию влияние.

Работа надданной статьей велась в период эпидемии коронавируса и, как следствие, мощного информационного воздействия на аудиторию со стороны как традиционных средств массовой информации, так и новых медиа. Таким образом, коронавирус стал одним из основных социальносетевых медиатопиков в соцсети «ВКонтакте». В результате исследования нами было обнаружено, что многие сообщества, посвященные различным жизненным сферам, начали публиковать контент, так или иначе связанный с названным заболеванием или намекающий на него, причем контент этот далеко не всегда можно считать качественным. Интересно то, что одни паблики размещали огромное количество постов соответствующей тематики, открыто навязывая аудитории данную тему, в то время как другие использовали стратегию так называемых информационных вбросов, подразумевающую публикацию меньшего числа постов, которые, как может изначально показаться, незаметны на фоне контента, отвечающего тематике группы. Иными словами, пользователи, обратившиеся к тому или иному сообществу с целью отдохнуть, развлечься, получить какую-либо информацию и т.д., вновь сталкиваются с темой, которая доминирует на всем медиапространстве, что, безусловно, оказывает влияние на сознание и поведение.

Огромный объем информации (в том числе и фейковой, имеющей манипулятивный характер) привел к массовой истерии. Было замечено активное проявление агрессии по отношению к тем, кто придерживается другой точки зрения на актуальные проблемы (во многом это связано с фактором анонимности, позволяющим пользователям открыто выражать свое мнение, с той свободой, которую предоставляет виртуальная коммуникация). В частности, аудиторией обсуждалась целесообразность введения карантина (режима самоизоляции) в стране. С учетом изменения ситуации данное противостояние трансформировалось в агрессивную коммуникацию сторонников и противников перчаточномасочного режима. Аналогичная ситуация наблюдалась в связи с появлением вакцины от коронавируса, отбором добровольцев для ее тестирования и непосредственно началом вакцинации.

По мере приближения голосования по поправкам в Конституцию Российской Федерации коронавирус был вытеснен на второй план социально-сетевым медиатопиком, связанным с борьбой положительно и отрицательно настроенных граждан по отношению к предлагаемым поправкам. Определенные группы, изначально посвященные другим сферам человеческой деятельности, были фактически превращены в площадку для политической агитации. Необходимо отметить, что в отличие от внутренней политики России, примером чего являлись поправки в Конституцию, вопросы, связанные с политической обстановкой в других странах, обсуждаются пользователями менее активно. В частности, не столь значительное внимание уделялось выборам президента Белоруссии, повлекшим за собой массовые протесты, и военному конфликту между Арменией и Азербайджаном в Нагорном Карабахе, что обусловлено анализом коммуникации 
именно в российском сегменте соцсети, для пользователей которого названные темы не являются приоритетными.

Таким образом, «ВКонтакте» является примером социальной сети, для которой огромное значение имеют актуальные, социально-значимые медиатопики, представленные на всем российском медиапространстве, а не только характерные для конкретной соцсети. Иными словами, медиакартина мира, формирующаяся в процессе коммуникации в данной социальной сети, во многом приближена к медиакартине мира, которую конструируют в сознании аудитории средства массовой информации. Данная особенность в сочетании с техническими возможностями платформы, на наш взгляд, позволяет рассматривать названный ресурс в качестве коллективного организатора, способного влиять на сознание и поведение массовой аудитории.

\section{Перспектива исследования}

Предложенная нами классификация социальных сетей представляет собой основу для дальнейшего исследования особенностей коммуникации в соцсетях, а также картины мира, которая формируется в процессе коммуникации. Предполагается глубокое изучение языковых способов формирования субкоммуникации в социальных сетях. Особый интерес представляют стратегии, в том числе и лингвистические, применяемые с целью формирования в сознании пользователей определенной картины мира. Кроме того, необходимо исследовать коммуникативное поведение аудитории, оказавшейся подверженной такому влиянию.

\section{Примечания}

${ }^{1}$ Медиапредпочтения детской аудитории в России / Mediascope. Режим доступа: https://mediascope.net/news/1097967 (дата обращения: 14.04.2020).

\section{Библиография}

Анисимова Е.Е. О целостности и связности креолизованного текста // Филологические науки. 1996. № 5. С. 74-85.

Анненкова И.В. Медиадискурс XXI века. Лингвофилософский аспект языка СМИ. М.: Изд-во Моск. ун-та, 2011.

Аргентова Т.Е. Социальная психология молодежи: учеб. пособие. Кемерово: Изд-во Кемеровск. гос. ун-та, 2015.

Безбогова М.С. Социальные сети как фактор формирования социальных установок современной молодежи: дис. ... канд. филол. наук. М., 2016.

Гуреева А.Н. Медиакоммуникационная практика российских вузов в новых медиа: социальные сети // Медиаскоп. 2016. Вып. 3. Режим доступа: http://www.mediascope. ru/?q=node/2150 (дата обращения: 02.04.2020).

Дукин Р.А. Институт социальных медиа в региональном пространстве коммуникационных практик: дис. ... канд. социол. наук. Саранск, 2017.

Ефимов Е.Г. Социальные группы в структуре социальных сетей (на примере «ВКонтакте») // Изв. Волгоградск. гос. техническ. ун-та. 2014. № 5. С. 63-67.

Жаркова А.А. Социальные сети: почему старшеклассники предпочитают живому общению виртуальное // Профилактика зависимостей. 2016. № 2 (6). С. 103-122. 
Зуйкина К.Л., Соколова Д.В. Социальные медиа в период парламентских выборов 2019 г. на Украине // Медиаскоп. 2019. Вып. 4. Режим доступа: http://www.mediascope. ru/2594 (дата обращения: 30.03.2020). DOI: 10.30547/mediascope.4.2019.9

Манойло А.В. Убить котенка, или Технологии конфликтной мобилизации в социальных сетях // Мировая политика. 2015. № 3. C. 1-12. DOI: 10.7256/2409-8671.2015.3.15973

Мансурова В.Д. Социальные сети и СМИ: учеб. пособие. Барнаул: Изд-во Алтайск. гос. ун-та, 2016.

Матусевич А.А. Актуальная лексика социальных сетей как отражение развития интернет-технологий // Вестн. Вятск. гос. гуманитар. ун-та. 2015. № 7. С. 74-79.

Морозова А.А. Проблемные моменты коммуникативного взаимодействия в социальных сетях // Вестн. Челябинск. гос. ун-та. 2014. № 26. С. 76-80.

Муронец О.В. Контент социальных сетей: тенденции и закономерности // Медиаскоп. 2015. Вып. 3. Режим доступа: http://www.mediascope.ru/1812\#25 (дата обращения: 04.04.2020).

Першина Е.Д. Принципы выбора российскими новостными медиа площадок для создания групп в социальных сетях // Медиаскоп. 2017. Вып. 2. Режим доступа: http:// www.mediascope.ru/2304 (дата обращения: 02.04.2020).

Садыгова Т.С. Социально-психологические функции социальных сетей // Вестн. науки ТГУ. 2012. № 3 (10). С. 192-194. 